\title{
Nota sobre Livio, XLIII, 3. La fundación de la Colonia de Carteia
}

\author{
M. ${ }^{a}$ JosÉ PENA *
}

La fundación de la colonia de Carteia en el año 171 a.C. es un tema complicado, discutido, que ha hecho correr bastante tinta y que probablemente seguirá siendo un polo de atracción para los historiadores por tratarse de la primera colonia latina - al menos la primera atestiguada por las fuentes- establecida fuera de la Península italiana. Yo no tengo la mínima aspiración de resolver el problema, pero si querria hacer algunas consideraciones sobre el texto de Tito Livio que relata el establecimiento de la colonia. Puesto que lo que aquí presento son tan sólo unos breves apuntes, la bibliografía será la estrictamente necesaria; para ulteriores ampliaciones, remito a los trabajos citados, donde puede leerse toda la historia de la polémica.

Tito Livio, XLIII, 3: «Et alia noui generis hominum ex Hispania legatio uenit. Ex militibus Romanis et ex Hispanis mulieribus, cum quibus conubium non esset, natos se memorantes, supra quattuor milia hominum, orabant ut sibi oppidum, in quo habitarent, daretur. Senatus decreuit, uti nomina sua apud L. Canuleium profiterentur eorumque, si quos manumisissent/manumisisset, eos Carteiam ad Oceanum deduci placere, qui Carteiensium domi manere uellent, potestatem fieri, uti numero colonorum essent, agro adsignato, latinam eam coloniam esse libertinorumque appellari».

El texto latino presenta una variante en los manuscritos y ello está en el origen del conflicto y las especulaciones. Sin embargo, el problema no es uno sino dos: 1 . la variante manumisisset/manumisissent, con el

* Universidad Autónoma de Barcelona. 
consiguiente cambio de sujeto; 2. las diferentes puntuaciones que los estudiosos han establecido en el texto. Las variantes básicas son: 1. ... uti nomina sua apud $L$. Canuleium profiterentur eorumque, si quos manumisissent; «inscribieran ante L. Canuleio sus nombres y los de aquellos a quienes ellos hubieran manumitido»; 2. ... uti nomina sua apud $L$. Canuleium profiterentur; eorumque si quos manumisisset, "inscribieran ante L. Canuleio sus nombres; si él hubiera manumitido a algunos de éstos...".

Además, hay que tener en cuenta que Livio no transcribe el decreto ni completo ni literalmente; basta comparar lo que transcribe del senatusconsultum de Bacchanalibus en XXXIX, 18, y el texto epigráfico conservado para tomar conciencia del problema.

Hay que tener en cuenta el hecho de que la mayoria de las ediciones del texto de Livio ${ }^{1}$ dan la primera variante, que es la transmitida por el Codex Vindobonensis, y ésta es en realidad la lectura tradicional, seguida por Galsterer ${ }^{2}$, Knapp ${ }^{3}$, Fabre ${ }^{4}$, Richardson ${ }^{5}$ y otros autores. Sin embargo, hace unos años, Saumagne ${ }^{6}$ estableció una puntuación totalmente distinta — variante dos- que más adelante comentaremos en detalle.

¿En qué consiste la diferencia? En la primera variante, son los hijos ex militibus Romanis et ex Hispanis mulieribus quienes deben inscribir no sólo sus nombres sino también los nombres de aquellos a quienes ellos hayan manumitido y que se convertirán también en ciudadanos de la colonia. La principal objección a esta solución es que estos individuos no estaban en situación de manumitir a nadie; por otra parte es difícil expli-

1 Guillaume BUdE (Les Belles Lettres) y TEUBNER: ... profiterentur eorumque, si quos manumisissent; Loeb: ...profiterentur eorumque, si quos manumisissent, eos Carteiam ... placere.

${ }^{2}$ B. GalstereR: Untersuchungen zum römischen Städtewesen auf del iberischen Halbinsel, págs. 7-9. Berlín 1971.

${ }^{3}$ R. C. KNAPP: Aspects of the Roman Experience in Iberia 206-100 BC, págs. 116-120; págs. 118-119: "A second group was to be composed of the freed slaves of the soldiers'sons, who were to be presented before Canuleius, the praetor in Spain, for manumission". Vitoria 1977.

${ }^{4} \mathrm{G}$. Fabre: "Les affranchis et la vie municipale dans la Peninsule Ibérique sous le Haut-Empire romain: quelques remarques", Actes du Colloque 1973 sur l'Esclavage, págs. 419-457, véase pág. 420 y nota 11. Besançon 1976.

${ }^{5} \mathrm{~J}$. S. RichaRdSON: Spain and the development of Roman imperialism, 218-82 BC, Cambridge University Press, pág. 119 y pág. 162. 1986.

${ }^{6}$ Ch. Saumagne: "Une colonie latine d'affranchis": Carteia (Tite Live, H. R., 43, 8), Revue historique de droit français et étranger, $\mathrm{XL}, 1962$, págs. 135-152. Idem, Le droit latin et les cités romaines sous l'Empire, págs. 60-71. Paris 1965. 
car la eventual presencia de un grupo de antiguos esclavos en el cuerpo ciudadano y todavía más imaginar que fueran precisamente ellos quienes dieran el apelativo (libertinorum) a la colonia.

La segunda variante tiene, en mi opinión, muchas más objeciones, a pesar de su buena acogida por ciertos historiadores que siguen más o menos fielmente a Saumagne, autor de la puntuación y traducción utilizada en gran medida por Humbert, Cels y Garcia Moreno. Dicho autor tradujo: «Le Sénat décréta: a) qu'ils feraient la déclaration nominale de leur identité auprès de Canuleius; b) et que ceux d'entre eux (eorumque si quos) que (Canuleius) affranchirait; c) ceux-là le Sénat décidait qu'ils fissent l'objet d'une déduction (coloniaire) à Carteia sur la mer».

\section{OBJECIONES HISTÓRICAS}

1.1. Saumagne imaginó que estos supra quattuor milia hominum, cuya embajada fue a Roma para pedir un oppidum donde establecerse, eran esclavos y como tal debian ser manumitidos. A esta idea se le pueden hacer numerosas objeciones: a) Livio habla de mulieres, no de seruae, ni de ancillae ni de nada similar; b) ¿es que en Hispania sólo había esclavas para los vencedores? como dice García Moreno ${ }^{7}$, ésto repugna toda lógica; c) ¿cómo un colectivo de esclavos iba a poder organizarse para enviar una delegación a Roma? ¿cómo iban a tener la suficiente importancia para ser recibidos por el senado y para que además éste emitiese un senatusconsultum a su favor?

1.2. Sin embargo, para mí, el inconveniente mayor es la oración condicional. Si la colonia debía establecerse tan solo con el grupo que Canuleio manumitiera -eorumque si quos manumisisset, si hubiese manumitido a algunos de éstos"-, ¿qué ocurrió con los que no fueron manumitidos? ¿quedaron como esclavos? ¿en base a qué criterio se hizo la selección? ¿aceptaron por las buenas esta diferencia?, son preguntas que nadie resuelve y que ni siquiera se abordan.

1.3. Por otra parte, hay que tener en cuenta el pluscuamperfecto manumisisset-ent: si la oración condicional se une a la de eos... deduci

7 L. A. García Moreno: "Sobre el decreto de Paulo Emilio y la "turris Lascutana", Epigrafia hispánica de época romano-republicana, págs. 195-218. Zaragoza 1986. 
(variante dos), parece que la acción de manumitir es posterior a la de inscribir los nombres y anterior a la de establecer la colonia; pero si se puntua correctamente el texto, es evidente que la acción de manumitir es anterior a la de inscribir los nombres y en consecuencia las teorías de Saumagne y sus seguidores caen por su base.

\section{OBJECIONES FILOLÓGICAS. ANÁLISIS DEL TEXTO LATINO}

2.1. Si uno lee con detenimiento el texto latino, se da cuenta de que, al menos aparentemente, la oración senatus decrevit... tiene cinco completivas: $1{ }^{a}$ uti... profiterentur; $2{ }^{a}{ }^{a}$ eos... deduci placere; $3 .{ }^{a}$ potestatem fieri uti...; $4 .^{\text {a }}$ eam coloniam esse...; 5. ${ }^{a}$ libertinorum apellari. La primera es una completiva de ut con subjuntivo; las cuatro restantes son oraciones de infinitivo. ¿Por qué esta variatio? en mi opinión, el quid de la cuestión está en piacere, verbo empleado normalmente en los decretos del senado y que admite tanto la construcción con infinitivo como con ut y subjuntivo. Aunque Livio no reproduce ni literalmente ni en su totalidad el decreto del senado, no obstante la comparación del texto liviano con textos epigráficos de índole jurídica puede ayudarnos a un análisis del texto más correcto. El texto del decreto de L.Aemilius Paulus, del año 189 a.C., dice: L.Aemilius decreivit utei.... leiberei essent. agrum oppidumque... possidere habereque iovsit. La primera parte del decreto está expresada por decrevit seguido de una completiva de ut con subjuntivo; la segunda por iovsit seguido de una oración con dos infinitivos. Si esta comparación fuera válida, podría pensarse: a) que Livio ha omitido un verbo iusit del cual dependerían los infinitivos; b) o bien que placere podría estar en forma personal (placuit) y en tal caso de él dependerían los infinitivos. Pero si recurrimos a la comparación con la Tabula Siarensis ${ }^{8}$, constatamos que en este texto, placere, en infinitivo, encabeza varios de los párrafos del senatusconsultum, aunque en este caso siempre rija ut y subjuntivo; sin embargo, frases como la siguiente no dejan lugar a dudas: Livio, XXXIII, 43, 2, partes censuerunt placere con-

${ }^{8} \mathrm{~J}$. GonZALEZ, "Tabula Siarensis, Fortunales Siarenses et municipia civium romanorum", $Z P E$, 55. 1984, págs. 55-100. Idem, "Apéndice. Texto y traducción de la Tabula Siarensis (nueva edición)", Estudios sobre la Tabula Siarensis, Anejos de Archivo Español de Arqueologia IX, págs. 305-315. Madrid 1988. 
sules prouincias sortiri. Como consecuencia de todo lo dicho, el texto debe ser analizado: senatus decreuit uti...profiterentur eorumque... /senatus censuit] placere: $1{ }^{a}$ eos...deduci, $2{ }^{a}$ fieri potestamen uti..., $3{ }^{a}$ eam

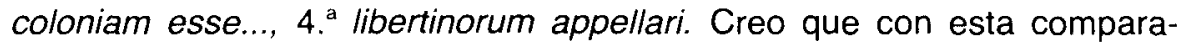
ción y este análisis el texto se comprende mejor, pues es evidente que refleja dos partes del senatusconsultum: en la primera el senado decreta lo que los peticionarios deben hacer; en los artículos posteriores se recogen las resoluciones del senado, las acciones que ha decidido llevar a cabo para solucionar el problema. Quizás Livio ha conservado más de lo que parece de la estructura del texto jurídico, pero to ha reducido tanto que no resulta de fácil comprensión.

Una cosa que hay que preguntarse y es importante por la interpretación histórica que supone es: ¿dónde termina el período de ut con subjuntivo y dónde empieza la serie de oraciones de infinitivo dependientes de placere? En realidad, todo nos conduce siempre a eorumque si quos manumisisset/-ent, oración que hay que analizar detenidamente.

2.2. Lá conjunción -que. Rubio ha estudiado de modo preciso y claro que el empleo de las distintas conjunciones copulativas latinas es mucho más sistemático de lo que en general se cree y precisamente -que es un término doblemente caracterizado - tanto frente a et como frente a ac-que el hablante usa cuando los dos términos implicados "aparecen como estrechamente unidos o lógicamente equivalentes" ${ }^{9}$. A este respecto, son significativas las definiciones del Dictionnaire étymologique de Ernout-Meillet ${ }^{10}$. ET: particule servant à unir deux mots ou deus phrases. -QUE: particule enclitique unissant deux mots ou deux membres de phrase (en ambos casos la cursiva es mía). Creo que es evidente que en el texto que nos ocupa -que une dos términos estrechamente unidos ya que se refieren al mismo sustantivo:

$\begin{array}{ll} & \text { sua } \\ \text { nomina } & \text {-que } \\ & \text { eorum }\end{array}$

En consecuencia, me parece que se está forzando el texto latino de modo inconveniente cuando se convierte en oraciones copulativas... nomina sua profiterentur; eorumque... deduci placere. Y no sólo por todo lo

${ }^{9}$ L. RuBlo, Introducción a la sintaxis estructural del Latín, vol. II, págs. 183-184. Barcelona 1976.

${ }_{10}$ A. Ernout y A. Meillet, Dictionnaire étymologique de la Langue Latine, págs. 310 y 8.37. Paris 1939. 
que acabo de exponer, sino también porque creo que el corte entre la completiva de ut con subjuntivo y la serie de completivas de infinitivo está precisamente entre manumisisset/-ent y eos.

2.3. Todo el mundo sabe, aunque parece que en este caso se olvida, que detrás de la conjunción si, quis, quae, quid se usa en lugar de aliquis y es por tanto un pronombre indefinido.

2.4. si seguido del pluscuamperfecto de subjuntivo. Uno de los usos primeros y más antiguos (Livio reproduce en cierta medida el texto original) del pluscuamperfecto de subjuntivo es expresar una idea irreal de pasado ${ }^{11}$. Se prescinde demasiado fácilmente de la idea de eventualidad expresada por el indefinido quos y el plusc. de subjuntivo manumisissetent.

En conclusión creo que eorumque y la oración condicional deben ser unidas sintácticamente a lo que antecede (que es como puntuan todas las ediciones citadas) y no a lo que sigue. Es preciso encontrar una solución respetando el texto latino.

\section{DIVERSOS ESTUDIOSOS HAN INTENTADO EN ESTOS ULTIMOS AÑOS ESCLARECER EL SIGNIFICADO DEL PASAJE LIVIANO}

3.1. Humbert ${ }^{12}$ adopta la puntuación y traducción de Saumagne, pero rechaza totalmente la idea de la condición servil de los cuatro mil peticionarios; este autor ha encontrado una ingeniosa solución, digna de un jurista pero totalmente hipotética. En su opinión, todo se puede explicar por un conflicto negativo de ciudadanias. No reconociendo la legitimidad de la unión de sus padres, la solución romana del conflicto no les daba más que una ciudadanía posible: la peregrina (por las madres). Pero esta solución romana no prejuzga la normativa que se podía aplicar al conflicto en ámbito local. Supongamos (la cursiva es mía) que para que haya matrimonium iustum según la ley española, la unidad de la ciudadanía de los esposos no haya sido condición requerida: según la costumbre española, que

\footnotetext{
$12 \mathrm{M}$. HUMBert, "Libertas id est civitas: autour d'un conflit négatif de citoyennetés au II s. avant J.C.", MEFRA, 88, págs. 221-242. 1976,1.
} Iona 1948

"M. BAssols, Sintaxis histórica de la Lengua Latina, tomo II,1, págs. 544-545. Barce- 
nous ne connaissons pas, mais que l'on peut supposer telle, el hijo habria sido unido al padre y considerado como un no-español, como un romano. Asi se llega a un conflicto negativo de ciudadania: peregrinos para la ley romana, romanos para la ley española.

La hipótesis es interesante, pero no deja de ser éso, una hipótesis, pues el autor no aduce ningún paralelo antiguo, por remoto que sea, para intentar demostrar que la ley hispana era asi.

3.2. Por su parte J. Cels ${ }^{13}$, en un largo y documentado estudio cuyo objetivo es esclarecer el significado del término libertinus, también ha considerado el problema del origen de la colonia de Carteia. Acepta sin reservas la lectura, la puntuación y la traducción de Humbert (que es en realidad la de Saumagne) y también la teoria explicativa que convierte en apátridas a los cuatro mil peticionarios. En su opinión, la manussio pronunciada por el pretor es una especie de trámite o de ficción legal para acceder a la ciudadanía, en este caso latina. Es posible que así fuera en algunas ocasiones, pero me parece claro por el texto de Livio que esto no era un trámite "necesario": los Carteienses no parecen estar incluidos (en ninguna de las variantes) entre los manumissi y sin embargo pasan de peregrinos a colonos, lo cual significa que también adquieren la ciudadanía.

3.3. García Moreno ${ }^{14}$ no transcribe el texto latino, pero de su traducción se deduce que sigue la puntuación de Saumagne, aunque traduce mucho más fielmente que éste la oración condicional. A este estudioso le parece fuera de toda lógica el hecho de que en Hispania no hubiera más que esclavas para los vencedores; estableciendo una relación con el decreto de Emilio Paulo y siguiendo una idea que ya expuso Mangas ${ }^{15}$, piensa que el problema de Carteia sólo podría encontrar explicación en el caso de suponer en el Mediodía peninsular una inmensa masa de población esclava, que llegase a constituir comunidades urbanas completas. Algo semejante a lo que ocurría en el dominio norteafricano de Cartago, donde habia comunidades libias completas bajo un estatuto de dependencia servil. La hipótesis es seductora y en cierta medida quizás válida, pero, en mi opinión, el problema es siempre el mismo: ¿tanta servidumbre comunitaria había en la Bética que los sol-

${ }^{13} \mathrm{~J}$. Cels-Saint-Hilaire, "Les libertini: des mots et des choses", DHA, 11, págs. 331379. 1985.

${ }^{14}$ Garcia Moreno, "Sobre el decreto de Paulo Emilio...", cit.

15 J. MANGAS, "Servidumbre comunitaria en la Bética prerromana", Memorias de Historia Antigua, I, págs. 151-161. Oviedo 1977. 
dados romanos no encontraron ninguna mujer libre? También esto está por demostrar.

\section{TRAS COMENTAR LAS HIPÓTESIS AJENAS, INTENTARÉ EXPO- NER LA MIA, QUE ES SIN LUGAR A DUDAS LA MÁS SIMPLE}

Puesto que yo siempre he sentido un cierto rechazo hacia la puntuación y traducción de Saumagne, me he esforzado por encontrar una posible solución acorde con lo que a mi me parece la lectura y la puntuación correctas (véase supra). Observando las distintas ediciones y las distintas traducciones, me he dado cuenta de un detalle: todos los que ponen punto y coma detrás de manumisissent, adoptan la lectura del verbo en plural; todos los que ponen punto y coma detrás de profiterentur, adoptan la lectura de manumisisset en singular. Sin embargo, nadie propone la tercera posibilidad: ... profiterentur eorumque, si quos manumisisset; es decir, con la puntuación correcta y el verbo en singular. En este caso la traducción sería "...que inscribieran ante Canuleio sus nombres y los de aquellos a quienes él hubiese manumitido (en el caso que hubiese manumitido a algunos)".

Es una hipótesis muy simple y en consecuencia simplifica mucho los problemas. Para intentar defenderla, he de recurrir una vez más al decreto de Emilio Paulo y también a la situación histórica en que $\mathrm{L}$. Canuleio llegó a la Ulterior. El decreto de Emilio Paulo, documento sumamente conocido y comentado, datado en el año 189 a.C., es un ejemplo muy temprano de manumisión oficial por parte de un general romano; en este caso se trata de una manumisión colectiva, en cuya problemática no vamos a entrar porque ha sido recien y ampliamente desarrollada por García Moreno ${ }^{16}$ y también por Marco Simón ${ }^{17}$. Lo que nos interesa es que el precedente de la manumisión oficial existe ya en la hispanidad romana y que es lícito suponer que el caso de la turris Lascutana no fuera el único. La situación en la que L. Canuleio llegó a la Ulterior me parece también importante. Justo en el capítulo anterior, Livio nos cuenta

16 Garcia Moreno, "Sobre el decreto de Paulo Emilio...", cit.

17 F. MARCo Simon, "La manumissio oficial de Emilio Paulo en el marco de la politica internacional romana del siglo II a.C.", Epigrafía hispánica de época romano-republicana, págs. 219-225. Zaragoza 1986. 
que el senado recibió a los legados de algunos pueblos de ambas Hispanias que iban a quejarse de la avaricia y soberbia de los magistrados romanos y a pedir que no se les expoliase y vejase con más ignominia que a los enemigos: hubo también un senatusconsultum, se abrió un proceso que no condujo a ninguna condena, pero sin embargo los hispanos obtuvieron del senado algunas garantías para el provenir. En este ambiente no sería de extrañar que Canuleio hubiera dado una prueba de la liberalitas romana mediante algún acto de manumisión oficial, bien fuera colectiva bien personal; en tal caso, el senado, al mismo tiempo que resolvía el problema de los cuatro mil peticionarios, se ocupaba también de donde establecer a los beneficiarios de la manumisión de Canuleio.

En esta hipótesis, los demás problemas no se plantean: los cuatro mil peticionarios no son esclavos y en consecuencia no necesitan ser manumitidos; tampoco ellos manumiten a nadie. Por otra parte, la interpretación de la expresión liviana nouum genus hominum también se simplifica. Me parece excesiva la opinión de Humbert cuando, de acuerdo con su teoria, habla de cétonnement qui accueillit à Rome la delegation de ces apatrides, de ces hommes d'une condition juridique jamais vue» ${ }^{18}$. García Moreno atribuye la expresión a la extrañeza de Livio ante un masa de población servil. A mí la expresión me parece lógica y nada extraña, referida sencillamente a los hijos de soldados romanos y de mujeres hispanas, es decir a la primera generación de hispano-romanos llegada a la edad adulta; se trata del primer establecimiento, en términos absolutos, de hijos de soldados romanos fuera de Italia, puesto que Hispania fue la primera provincia romana después de Sicilia. Itálica había sido establecida para la generación de los padres y son precisamente 35 años los que separan ambos establecimientos.

Con mi propuesta, la tesis de $\mathrm{J}$. Cels no queda invalidada ni siquiera cuestionada. Si el término libertinus es, según sus conclusiones, un vocablo ambiguo que insiste sobre el carácter reciente de la ciudadanía pero deja en la sombra el estatuto de origen -esclavo o peregrino-, nada más propiado para una ciudad constituida por un nouum genus hominum, por algunos (si quos) manumissi (cuyo estatuto anterior desconocemos) y por peregrini carteieneses. Todos se habían convertido en libertini.

Como las anteriormente comentadas, también la mía es una simple hipótesis; sin embargo, confio en que merezca una cierta atención por

${ }^{18}$ Humbert, “Libertas id est civitas...», cit. pág. 232. 
dos razones: porque parte de una lectura del texto que respeta la sintaxis latina; y porque simplifica notablemente el cúmulo de problemas que la interpretación de este texto ha generado hasta ahora.

Traducción: "Vino de Hispania otra delegación de una nueva clase de hombres. Recordando que habían nacido de soldados romanos y de mujeres hispanas, con las que no existían matrimonio legítimo, más de cuatro mil, pedían que se les diese una ciudad en la cual vivir. El senado decretó que inscribieran ante $L$. Canuleio sus nombres y los de aquellos a quienes él hubiese manumitido; decidió (acordó decidir) establecerlos en Carteia, junto al Océano, permitir que estuviesen en el número de los colonos los carteienses que quisieran pemanecer en su ciudad, una vez les fuera asignado un lote de tierra, que fuera una colonia de derecho latino y que se llamara de los libertini". 